\title{
Evaluation of behavior and performance of the braced/ unbraced four story of steel frame with semi rigid connection
}

\author{
Daniel Rumbi Teruna ${ }^{1, *}$ \\ ${ }^{1}$ Department of Civil Engineering, Universitas Sumatera Utara, Medan, Indonesia
}

\begin{abstract}
Structural analysis and design with taken into account the flexibility of the beam to the column connections of steel frameworks takes on importance of the growing development and utilization of new commercial software. However, for design purposes, the beam to the column connection are usually considered to be either pinned or fully rigid, and drastically simplifies the analysis and design procedures. In this paper, a four story of unbraced and concentric braced steel moment resisting frame having different connection stiffness is analysed using linear and nonlinear static procedure. In the finite element modelling, the semi rigid connection is modelled by rotational spring having linear moment and rotation relationship. To account the inelastic behaviour of beam and column members, concentrated plastic hinges based on FEMA 356 are applied for both ends of the member. It was found that, the response quantity of the unbraced frame are influenced by the flexibility connection. However, for the braced frame the effect of the initial connection stiffness parameter on the response quantity can be neglected due to present of the braces. Furthermore, the higher the initial connection stiffness parameter, the smallest the story drift index. Moreover, the present of the braces at the moment resisting frame (braced frame) reduce the sensitivity of the connection stiffness on the behaviour and the performance frame under consideration.
\end{abstract}

\section{Introduction}

Conventional analysis and design of steel structures are generally performed under the assumption that the beam to the column connection are either infinitely rigid or perfectly pinned. The validity of these assumption may be questionable for cases in which the stiffness of the connection fall between the fully rigid and ideally pinned. The concept of semi rigid connections is introduced in several codes $[1,2]$. The connection are classify by their strength as well as their ductility. The strength classification of connection is based on the relative resistance moment of the connection compared to moment resistance of the beam. Steel frames with semi rigid connection are widely used in different countries because more economically than rigidly connected frame $[3,4]$.

Degertekin and Hayalioglu [5] performed nonlinear analysis of the three stories two bay frame and ten stories one bay frame with various of the connection rigidity. It was demonstrated that semi rigid connection modelling may create lighter frame providing the connection size parameter are selected appropriately. However, the story drift for semi rigid connection modelling is always larger than when connection is assumed as fully rigid. To reduce the excessive story drift, Danesh [4] investigate ten and fourteen story steel frames that is called mixed steel structure under ground motion records. In the mix steel structure, the external frames are designed with rigid connection while internal frames are designed with semi rigid connection. It was noted that interstory drift of mixed structure are very close to the rigid frame and capable of sustaining larger seismic excitation than the rigid structure with no excessive deformation.

The main objective of this paper is study the effect of the connection rigidity on the steel structures behaviour, performance, and formation of the plastic hinges at early stage to ultimate stage. For this purpose, a four stories steel frame with or without braces are investigated with four types of the initial connections rigidity.

\section{Semi rigid connection}

\subsection{Behavior of connection}

A connection of beam to column of plane frame have three DOF. However, effect of axial and shear deformation is, in general, small in relation to the rotational deformation [6]. The semi rigid connection in this present study is by relation between moment transmitted and relative rotation of the two interconnected members as illustrated in Figure 1. Although, the behaviour of the most connection shows the moment and

\footnotetext{
* Corresponding author: danielteruna@usu.ac.id
} 
rotation relation is not linear, the linear approach is, in general, acceptable for the analysis of frame, especially for low to moderate intensity of loads. Figure 2 shows an example of a typical beam to column connections, while the connection moment rotation curve is depicted in Figure 3 .

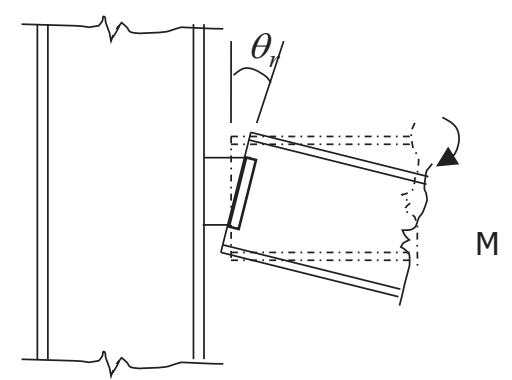

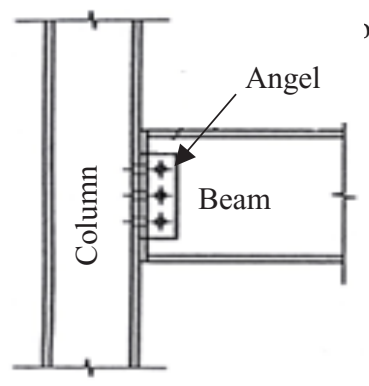

(a) Single/double angle

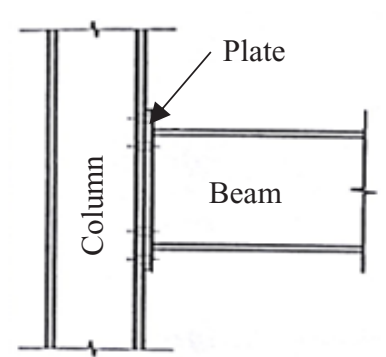

(c) Extended end plate

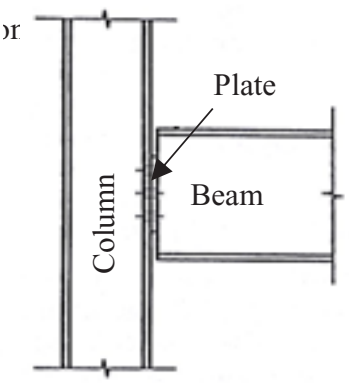

(b) Header plate

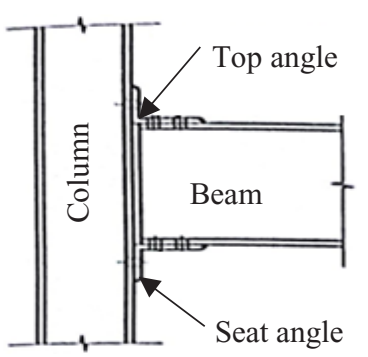

(d) Top and seat angle

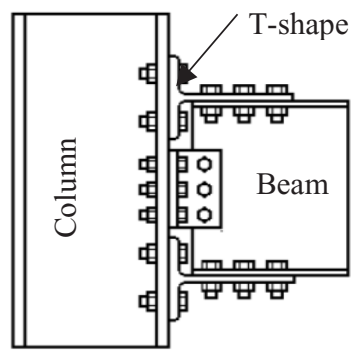

(e) T-stub

Fig. 2. Typical type of beam-column connection [6].

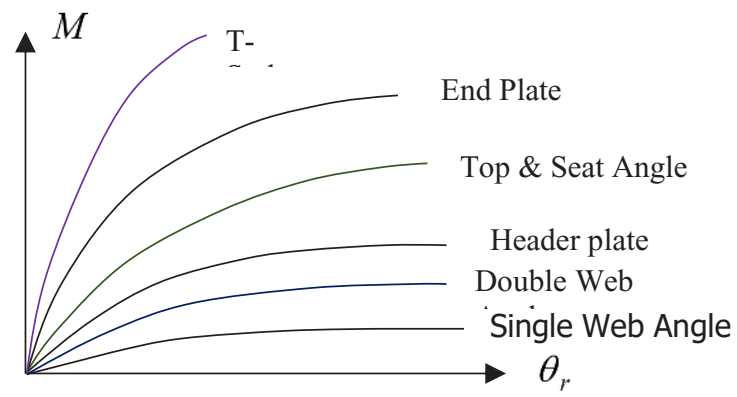

Fig. 3. Connections of moment-rotation curves [6].

\subsection{Classification of connection}

In engineering practice, the connections beam to column are assumed to be rigid, semi rigid, or pinned. The classification system of connections has presented by EC3 [2] and ANSI/AISC 360-10 [1]. EC3 proposed a classification of connections based on the two independent criteria expressed in term of rotational stiffness and strength, respectively. The boundary between rigid and semi rigid connections is determined in term of a non-dimensional initial connections stiffness parameters and rotation defined as:

$$
\bar{K}=\frac{K_{i} L_{b}}{E I_{b}}, \bar{\theta}_{r}=\theta_{r} \frac{E I_{b}}{M_{p b}}
$$

Where, $K_{i}$ is initial rotational stiffness of connections, and $M_{p b}, I_{b}$, and $L_{b}$ are the plastic moment, the moment of inertia, and the span of the beam, respectively. The classification of connections based on stiffness (Eq.1) are listed in table 1.

Table 1. Classification of connections [2]

\begin{tabular}{|l|l|c|}
\hline \multicolumn{2}{|c|}{ Connections } & $\bar{K}$ \\
\hline Rigid & Braced frames & $\bar{K}>8$ \\
\cline { 2 - 3 } & Unbraced frames & $\bar{K}>25$ \\
\hline \multirow{2}{*}{ Semi rigid } & Braced frames & $0.5 \leq \bar{K} \leq 8$ \\
\cline { 2 - 3 } & Unbraced frames & $0.5 \leq \bar{K} \leq 25$ \\
\hline Ideally pinned & $\bar{K}<0.5$ \\
\hline
\end{tabular}

Mazzolani and Piluso [7] proposed the values of $\bar{K}$ for various of connections as shown in Figure 4.

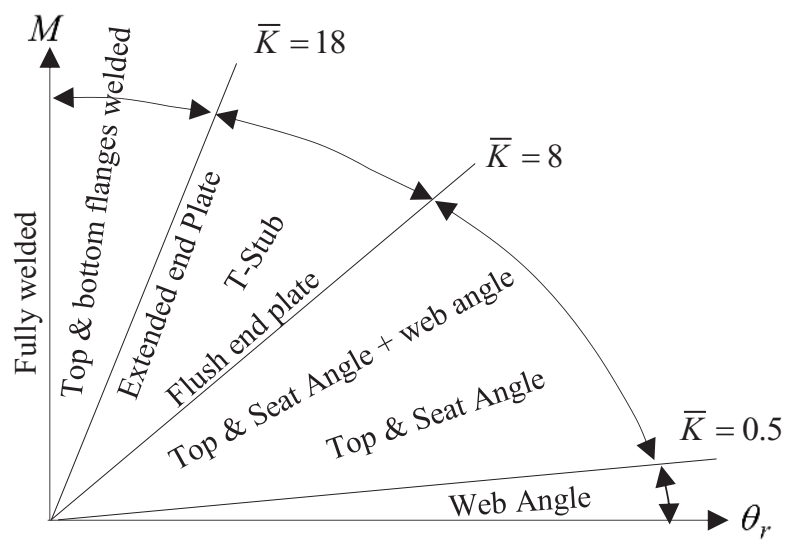

Fig. 4. Typical values of connections stiffness parameter [7].

\subsection{Connections modelling}

The most commonly approach used to describe momentrotation relation is to curve fit the experimental data with simple expression. Several analytical models have been developed which vary from a simple linear model to polynomial and exponential model [6,7]. Although, linear model is less accurate, however, it is very easy to use, and they provide a fairly accurate prediction of frame 
response. Therefore, a linear model is used in the present works through initial connection stiffness parameter $\bar{K}$.

\section{Nonlinear Static Procedures (NSP)}

Although THA is the most accurate analysis to evaluate seismic demand, the application NSP is generally considered to be more appropriate for seismic design due to its simplicity and ease to use. This is the reason why the NSP is known as the most use tool in the engineering practice for assessment of seismic behavior of structures, and currently has resulted in guidelines such as FEMA356 [8] and standards ASCE 41-13 [9].

NSP is conducted by applying the gravity loads followed by lateral load is gradually increased along a direction under consideration. The investigated building is pushed according to predefined lateral load pattern to obtain the target displacement. At each load step, the base shear and the roof displacement can be plotted to created capacity curve or pushover curve.

\subsection{Load pattern}

There are three lateral load patterns proposed in FEMA356, namely (a) inverted triangular distribution, (b) uniform distribution, (c) distribution of forces proportional to fundamental mode. the applicability lateral load pattern based on inverted triangular distribution on evaluation of seismic deformation demands using NSP were investigated by Ghaffarzadeh et al.[10], Kunnath and Kalkan [11]. It was found that in all cases, push (a) pattern provided fairly results to the mean time history analysis. In this paper, inverted triangular pattern based on site class $B, S_{s}=0.71 \mathrm{~g}$, and $S_{1}=0.67 \mathrm{~g}$ is applied in the pushover analysis.

\subsection{Structural performance level}

The seismic performance of a building structure is measured by the stage of damage under a certain seismic hazard in which is quantified by roof displacement and deformation of the structural members. Figure 5 shows force-deformation relation for plastic hinge in pushover analysis. There are five points labelled A, B, C, D, and E are used to define the force-deformation behaviour of the plastic hinge, and three points labelled IO (immediate occupancy), LS (life safety), and CP (collapse prevention) are used to define acceptance criteria for the hinge. There are six levels of structural performance in ASCE 41-13, i.e., Immediate occupancy (S-1), Damage control range (S-2), Life safety (S-3), Limited safety range (S-4), Collapse prevention (S-5), and Not considered (S-6).

The case study of building frame was designed based on design spectrum that constructed for DBE seismic hazard level according to Indonesian seismic design code. Target displacement in this study is determined based on the displacement coefficient method defined in ASCE 4113. This method is accomplished by modifying the elastic response of equivalent SDOF system with coefficient $C_{0}, C_{1}$, and $C_{2}$ is expressed as:

$$
\delta_{t}=C_{0} C_{1} C_{2} S_{a} \frac{T_{e}^{2}}{4 \pi^{2}} g
$$

where, $S_{a}$ is response spectrum acceleration at the effective fundamental period and damping ratio of the building, $g$ and is gravity acceleration, $T_{e}$ is effective fundamental period computed from Eq. (3).

$$
T_{e}=T_{i}\left(K_{i} / K_{e}\right)^{0.5}
$$

In which $T_{i}, K_{i}, K_{e}$ is the elastic fundamental period, elastic stiffness and the effective stiffness of the building in the direction under consideration, respectively, obtained by idealizing the pushover curve as a bilinear relationship. The procedures and explanation of the Eq. (2) to obtain the target of displacement is illustrated more detail in ASCE 41-13[9] and Teruna [12]. Plastic hinge modelling parameters and acceptance criteria for structural steel component using NSP is given in table 9.6 of ASCE 41-13 [9].

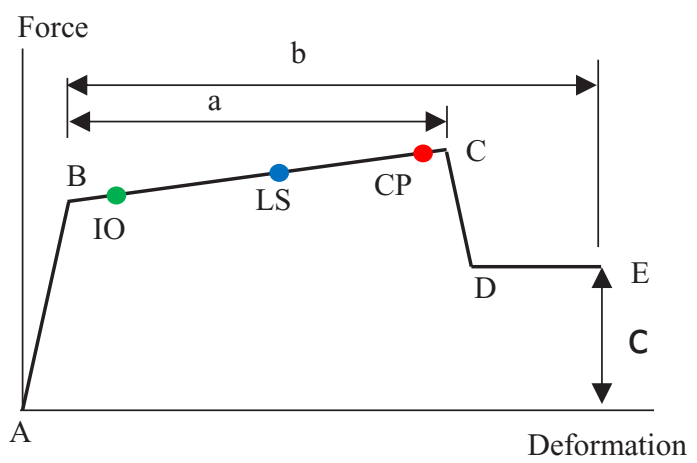

Fig. 6. Force-deformation for plastic hinge

\section{Description of evaluated building}

The building selected for this study is four stories of three bay moment steel frame with and without braces as shown in Figure 7a and Figure 7b. Moment resisting steel frame without braces is denoted as MR and moment resisting frame with braces is denoted as CB. There are four types of the initial connection stiffness parameters, $\bar{K}$ are considered in this study. i.e., $\bar{K}=6,10,14,25$ to present semi rigid connections. For the purpose of clarity, MR frames with semi rigid connections designated as $M R-6 \bar{K}, M R-10 \bar{K}, M R-14 \bar{K}, \quad$ and $M R-25 \bar{K}$, whereas CB frames designated as $C B-6 \bar{K}, C B-10 \bar{K}, C B-14 \bar{K}$, and $C B-25 \bar{K}$, respectively. All beams are WF $350 \times 175 \times 7 \times 11$ and all columns are WF 350x350x10x16. Next, the element of braces is hollow section with the following dimension $175 \times 175 \times 4.5 \mathrm{~mm}$ (BR1), and $175 \times 175 \times 4 \mathrm{~mm}$ (BR2) for first and second story, respectively. For remaining story, i.e., third and fourth story is designated as $150 \times 150 \times 4.5 \mathrm{~mm}$ (BR3) and 150x150x4mm (BR4). All material steel having yield stress $250 \mathrm{MPa}$.

In order to have the simulation more reasonable, the structure is designed to withstand realistic gravity load (dead load and live load). The magnitude of gravity loads 
each story is assumed to be $22 \mathrm{kN} / \mathrm{m}$ for dead load, and $8 \mathrm{kN} / \mathrm{m}$. Lateral loads is applied to investigated frame using static equivalent procedures

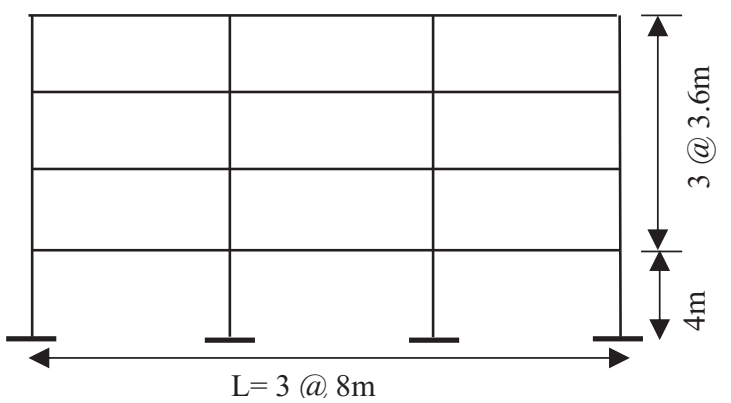

(a). Elevation view of MR system

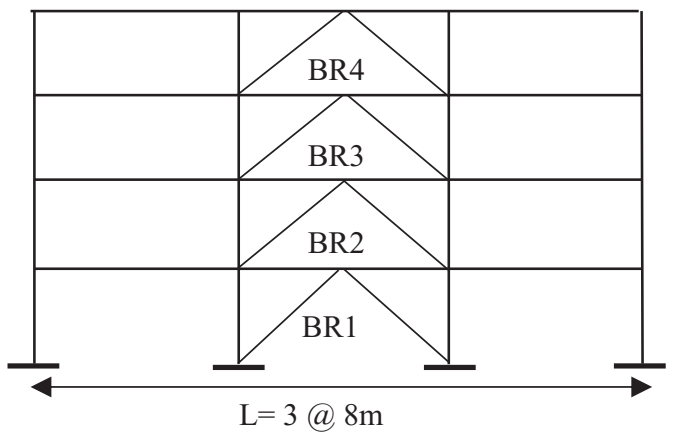

(b). Elevation view of $\mathrm{CB}$ system

Fig. 7. Model steel structures

\section{Discussion and results}

\subsection{Interstory drift index}

One of response parameters commonly used to evaluate seismic performance of a structure is inter-story drift. Figure 8 shows the inter-story drift for moment resisting frame (MR) with different initial connection stiffness parameter, $\bar{K}$.

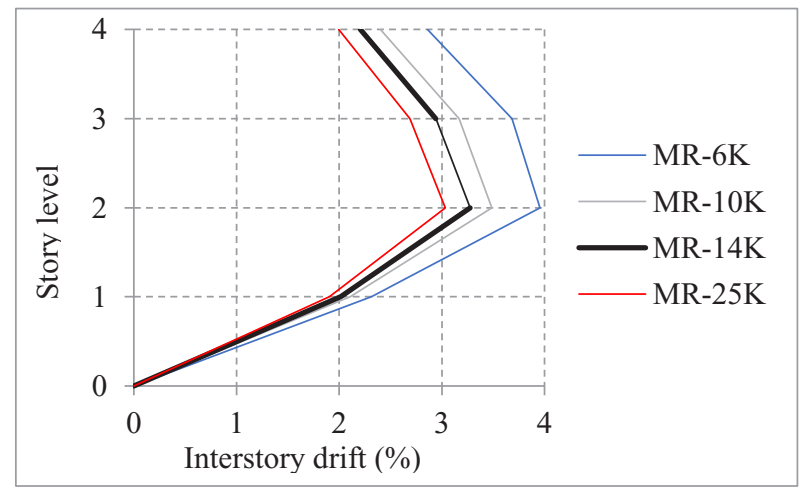

Fig. 8. Interstory drift index for MR frame

It was observed that the maximum inter-story drift occurred in the mid stories. The maximum of interstory drift of $3.95 \%$ occurs in the $M R-6 \bar{K}$. In addition, the higher the initial connection stiffness parameter, the smallest the interstory drift index. Furthermore, the relation between interstory drift versus story level for CB frame as shown in Figure 9. In general, interstory drift index is almost similar regardless the value of initial connection stiffness parameter. It was also noted that for braced framed with semi rigid connection $C B-6 K$ interstory drift on the top floor is slightly different with others story. Unlike MF frame in which the maximum of interstory drift occurs in the mid story, however, for $\mathrm{CB}$ frame, the maximum interstory drift occur in the top story. Moreover, the present of braces in the MRF frame (CB frame) reduced drastically the inter story drift.

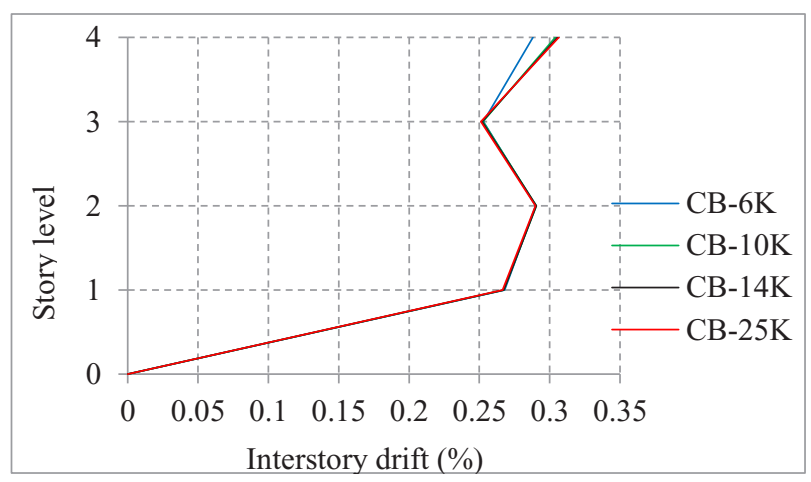

Fig. 9. Interstory drift index for $\mathrm{CB}$ frame

\subsection{Bending moments of beams/columns}

Structural analysis is carried out due to two cases of load combination, i.e., case 1: $1.2 \mathrm{DL}+1.6 \mathrm{LL}$, and case 2 : $1.2 \mathrm{DL}+0.5 \mathrm{LL}+1.0 \mathrm{EQ}$. Typical bending moments diagram for MR frame and $\mathrm{CB}$ frame under case1 is depicted in Figure 10. It can be seen that for exterior beams and columns, the bending moment diagram is similar shape, but different shape for interior beams and columns due to present of the braces.

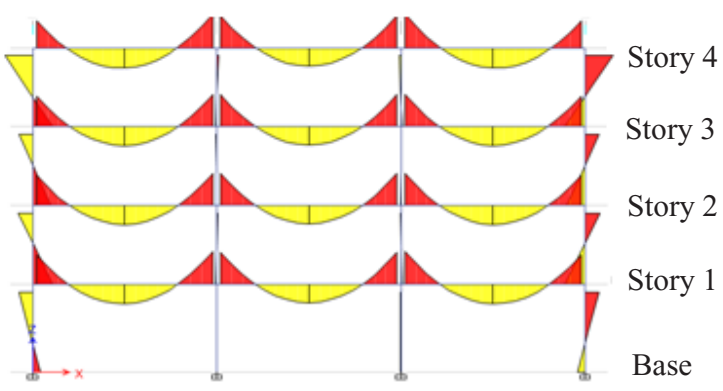

(a) Typical bending moment diagram for MR frame

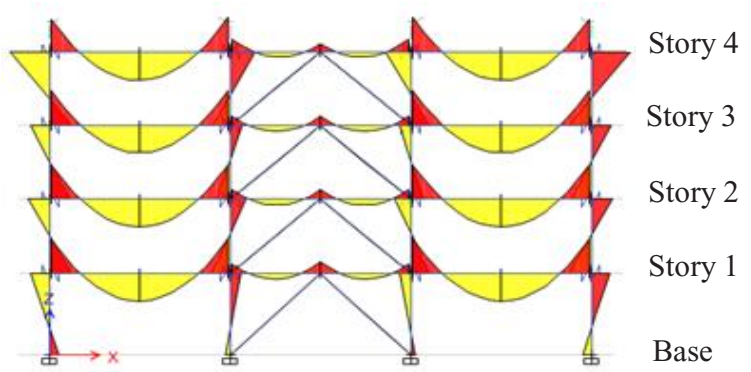

(b) Typical bending moment diagram for CB frame

Fig. 10. Bending moment diagram for case 1 
To account the influence initial stiffness connection parameter on the bending moment for both frames, the interior beam and exterior column of the first story to be investigated. For the purpose discussion and clarity, the symbols of the bending moment for the beam and column are shown in Figure 11 and the results is given in table 1.

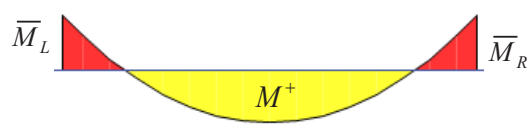

(a) Beam of MR frame

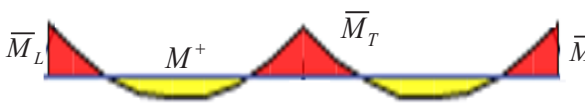

(b) Beam of CB frame

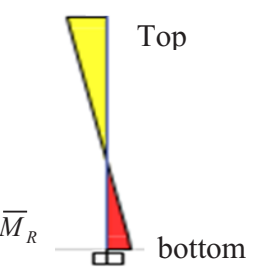

(c) typical column
Fig. 11. Identifications of the beam and column moment

Table 1. Comparison of bending moment for MR frame

\begin{tabular}{|c|c|c|c|c|c|}
\hline $\begin{array}{c}\text { Type of } \\
\text { connections }\end{array}$ & \multicolumn{2}{|c|}{$\begin{array}{c}\text { Beam bending } \\
\text { moment } \\
(\mathrm{kN}-\mathrm{m})\end{array}$} & \multicolumn{2}{c|}{$\begin{array}{c}\text { Column bending } \\
\text { moment } \\
(\mathrm{kN}-\mathrm{m})\end{array}$} \\
\cline { 2 - 6 } & $\bar{M}_{L}$ & $M^{+}$ & $\bar{M}_{R}$ & Top & Bottom \\
\hline MR-6K & 151 & 140 & 151 & 65 & -36 \\
\hline MR-10K & 165 & 126 & 165 & 69 & -38 \\
\hline MR-14K & 172 & 119 & 172 & 71 & -39 \\
\hline MR-25K & 180 & 111 & 180 & 74 & -41 \\
\hline RIGID & 186 & 105 & 186 & 75 & -42 \\
\hline
\end{tabular}

It was clearly that the initial connection stiffness parameter influenced on the bending moment either beams or columns member. The higher the initial connection stiffness parameter, the higher the bending moment at the both end of the beam or the column. However, the bending moment at the middle of the beam length decrease when initial connection stiffness parameter increases. In addition, the bending moment at the top of the column is higher compare to the bottom. Furthermore, table 2 shows the comparison of bending moment for $\mathrm{CB}$ frame under case 1 with different of initial connection stiffness parameter.

Table 2. Comparison of bending moment for CB frame (case1)

\begin{tabular}{|c|c|c|c|c|c|c|}
\hline $\begin{array}{c}\text { Type of } \\
\text { connect. }\end{array}$ & \multicolumn{3}{|c|}{$\begin{array}{c}\text { Beam bending moment } \\
(\mathrm{kN}-\mathrm{m})\end{array}$} & \multicolumn{2}{c|}{$\begin{array}{c}\text { Column } \\
\text { bending } \\
\text { moment } \\
\text { (kN-m) }\end{array}$} \\
\cline { 2 - 8 } & $\bar{M}_{L}$ & $M^{+}$ & & $\bar{M}_{R}$ & Top & $\begin{array}{c}\text { Botto } \\
\mathrm{m}\end{array}$ \\
\hline $\mathrm{CB}-6 \mathrm{~K}$ & 34 & 28 & 55 & 34 & 68 & -40 \\
\hline $\mathrm{CB}-10 \mathrm{~K}$ & 42 & 25 & 52 & 42 & 71 & -42 \\
\hline $\mathrm{CB}-14 \mathrm{~K}$ & 47 & 24 & 51 & 47 & 74 & -43 \\
\hline $\mathrm{CB}-25 \mathrm{~K}$ & 54 & 22 & 46 & 54 & 76 & -45 \\
\hline
\end{tabular}

Similar to MR frame, for CB frame the negative bending moment occurs at the both ends of the beam and increases as the initial connection stiffness parameter also increases. It was also noted that the bending moment at the top of the column is higher compare to the bottom. In contrast, the negative bending moment at the joint between beam and brace, and the positive bending moment of the beam decreases when the initial connection stiffness parameter increases. The negative bending moments of the beam for $\mathrm{CB}$ frame much smaller than MR frame since braces act as supported which reduced the length of the beam. In addition, the bending moment of the outer column of the MR frame is slightly smaller than the bending moment of the CB frame.

The comparison of the bending moment of case 2 for both MR and CB frames is listed in table 3 and table 4, respectively. Similar to case1, the negative bending moment of the beam increases when the initial connection stiffness parameter increases too. Negative bending moment of the left end side is smaller than the right end side because lateral load acts in a positive direction (to the right direction). Unlike to case1 while for case2, for MR frame, the bending moment in the top column is smaller than at the bottom. On the other hand, for CB frame, the effect of connection stiffness for both cases is similar, i.e., the bending moment in the top of column is always higher compare to the bottom.

Table 3. Comparison of bending moment for MR frame (case2)

\begin{tabular}{|c|c|c|c|c|c|}
\hline \multirow{2}{*}{$\begin{array}{c}\text { Type of } \\
\text { connect. }\end{array}$} & \multicolumn{3}{|c|}{$\begin{array}{c}\text { Beam bending } \\
\text { moment } \\
(\mathrm{kN}-\mathrm{m})\end{array}$} & \multicolumn{2}{c|}{$\begin{array}{c}\text { Column } \\
\text { bending } \\
\text { moment } \\
\text { (kN-m) }\end{array}$} \\
\cline { 2 - 7 } & $\bar{M}_{L}$ & $M^{+}$ & $\bar{M}_{R}$ & Top & Bottom \\
\hline CB-6K & 66 & 112 & 169 & 68 & 128 \\
\hline CB-10K & 74 & 102 & 183 & 63 & 115 \\
\hline CB-14K & 78 & 96 & 190 & 61 & 109 \\
\hline CB-25K & 83 & 90 & 198 & 58 & 103 \\
\hline RIGID & 86 & 85 & 204 & 56 & 98 \\
\hline
\end{tabular}

Table 4. Comparison of bending moment for CB frame (case2)

\begin{tabular}{|c|c|c|c|c|c|c|}
\hline $\begin{array}{c}\text { Type of } \\
\text { connect. }\end{array}$ & \multicolumn{4}{|c|}{$\begin{array}{c}\text { Beam bending moment } \\
(\mathrm{kN})\end{array}$} & \multicolumn{2}{c|}{$\begin{array}{c}\text { Column bending } \\
\text { moment } \\
(\mathrm{kN})\end{array}$} \\
\cline { 2 - 7 } & $M_{L}$ & $M^{+}$ & $\bar{M}_{T}$ & $M_{R}$ & Top & Bottom \\
\hline CB-6K & 21 & 24 & 44 & 31 & 53 & -13 \\
\hline CB-10K & 28 & 22 & 41 & 37 & 53 & -14 \\
\hline CB-14K & 32 & 21 & 40 & 42 & 55 & -15 \\
\hline CB-25K & 37 & 20 & 37 & 48 & 57 & -16 \\
\hline
\end{tabular}

\subsection{Pushover curves}

Capacity curves is obtained from nonlinear static procedures (NSP) for MR and CB frame are presented in Figure 12 and Figure 13. It can be seen that for MR frame, the higher the initial connection stiffness parameters the more ductile the frame behaviour. It was also demonstrated that for the initial connection stiffness parameter, $\bar{K}=25(M R-25 \bar{K})$ shows similar behaviour with rigid frame. Furthermore, the present of braces to MF frame (CB frame) can reduce the sensitivity of semi rigid connection on the capacity curve as depicted in Figure 13. 
It was also found that the capacity curve of $\mathrm{CB}$ frame increases compared to the capacity curve of MR frame. On the contrary, the top displacement of the $\mathrm{CB}$ frame decreases significantly compare to the MR frame.

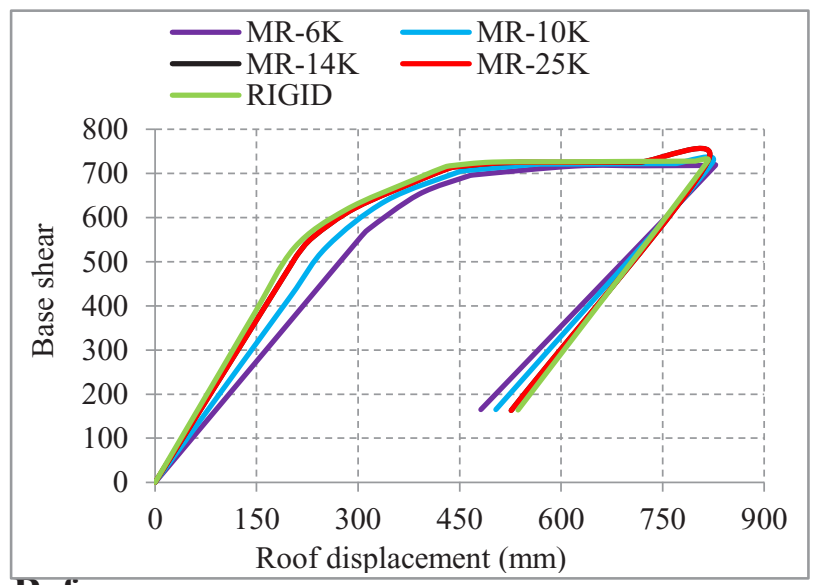

References
Fig. 12. Capacity curves of the MR frames

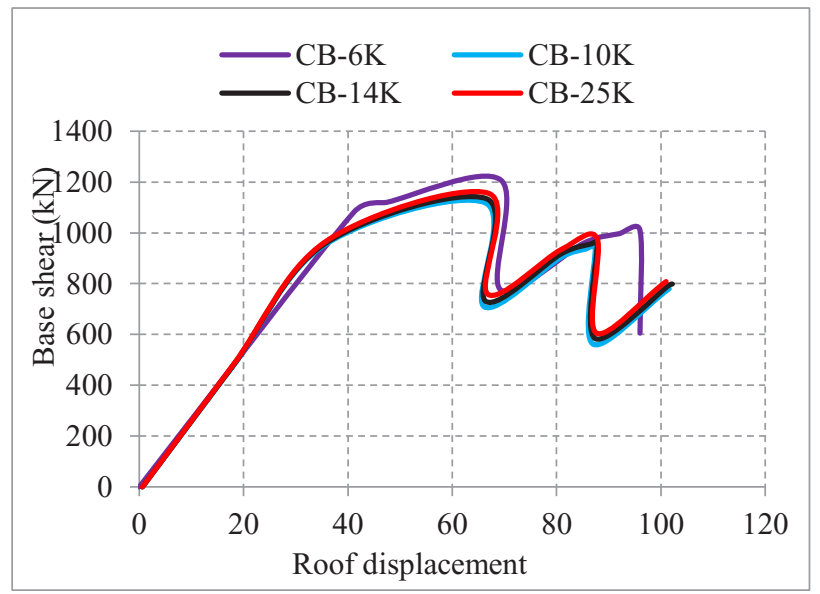

Fig. 13. Capacity curves of the CB frames

Online references will be linked to their original source, only if possible. To enable this linking extra care should be taken when preparing reference lists.

Further observation with regard to plastic hinge pattern in failure condition of MR and CB frames for the three type of connections stiffness are shown in Figure 14 and Figure 15, respectively. It can be observed that MR frame exhibit strong column-weak beam concept. All plastic hinges occurred in the beam and in bottom of the column. In this case, plastic hinges formed pattern for $M R-10 \bar{K}$, and $M R-14 \bar{K}$ experience similar pattern, in which the number of hinges are twelve (12) of IO level ( for beams) and two (2) of IO and CP level each at the column base.

Next observation revealed that for $M R-25 \bar{K}$, plastic hinges in the beams increases to fourteen (14) for IO level and four (4) in the column base. Plastic hinges in the column base consist of three (3) of IO level and one (1) of CP level. Unlike MR frame, for CB frame none plastic hinges occurs in the beams or columns. Plastic hinges occur only in the braces of the second and third floor. In other words, CB frame demonstrated the elastic deformation except at the braces.

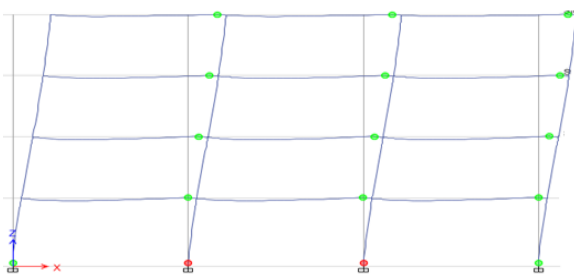

(a) MR-10K

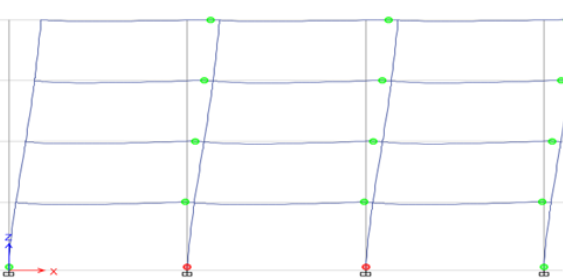

(b) MR-14K

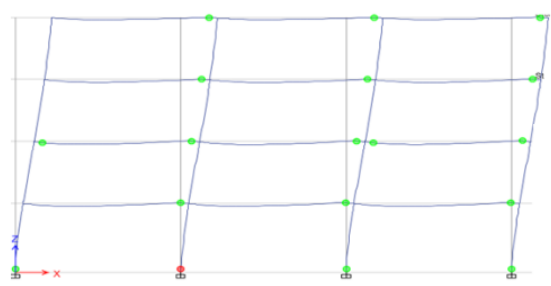

(c) MR-25K

Fig. 14. Formation of plastic hinges for MR

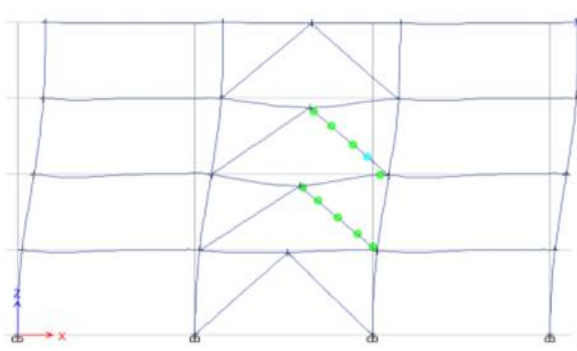

(a) $\mathrm{CB}-10 \mathrm{~K}$

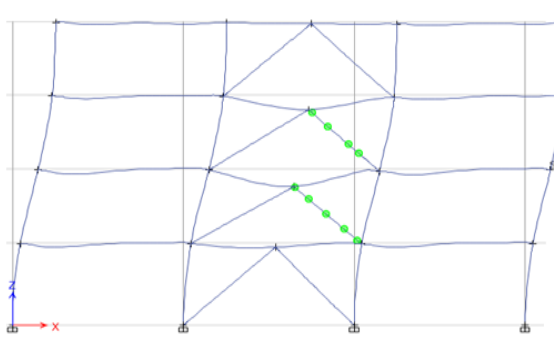

Story 4

Story 3

Story 2

Story 1

Base

(b) $\mathrm{CB}-14 \mathrm{~K}$
Story 4

Story 3

Story 2

Story 1

Base

Story 4

Story 3

Story 2

Story 1

Base

Story 4

Story 3

Story 2

Story 1

Base

Story 4

Story 3

Story 2

Story 1

Base 


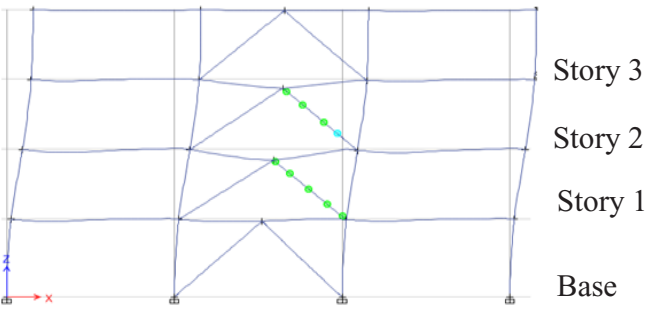

(c) $\mathrm{CB}-25 \mathrm{~K}$

Fig. 15. Formation of plastic hinges for $\mathrm{CB}$

\subsection{Evaluation of structural performance}

There are several methods to evaluate structural performance such as: interstory drift index, damage index, vulnerability index, and so forth. In this case, interstory drift index is used to evaluate the performance of the frame under consideration. Comparison of story drift index for both MR and CB frames is carried out based on linear and nonlinear procedures, and the results are listed in table 4 and table 5, respectively. There are three level and two range of structural performance level are described in Table C1-3 of FEMA 356 [8], that are immediate occupancy (S-1), life safety (S-3), collapse prevention (S-5), and two range, that are damage control range $(\mathrm{S}-2)$, and limited safety range $(\mathrm{S}-4)$.

Table 5. Comparison of the interstory drift index for MR

\begin{tabular}{|c|c|c|c|c|}
\hline \multirow{2}{*}{$\begin{array}{c}\text { Type of } \\
\text { connec. }\end{array}$} & \multicolumn{2}{|c|}{$\begin{array}{c}\text { Analysis first order } \\
\text { (linear) }\end{array}$} & \multicolumn{2}{c|}{$\begin{array}{c}\text { Pushover (nonlinear } \\
\text { static) }\end{array}$} \\
\cline { 2 - 5 } & $\begin{array}{c}\text { Max. } \\
\text { story } \\
\text { drift } \\
(\mathrm{mm}) \\
\text { using } \\
\mathrm{C}_{\mathrm{d}}=5.5\end{array}$ & $\begin{array}{c}\text { Inter-story } \\
\text { drift index } \\
(\%)\end{array}$ & $\begin{array}{c}\text { Perf. point } \\
(\mathrm{mm})\end{array}$ & $\begin{array}{c}\text { Linear/ } \\
\text { Non- } \\
\text { linear }\end{array}$ \\
\hline MR-6K & 465 & $3.14(\mathrm{~S}-4)$ & $337(\mathrm{~S}-2)$ & 1.38 \\
\hline MR-10K & 405 & $2.74(\mathrm{~S}-4)$ & $329(\mathrm{~S}-2)$ & 1.23 \\
\hline MR-14K & 374 & $2.53(\mathrm{~S}-3)$ & $318(\mathrm{~S}-2)$ & 1.18 \\
\hline MR-25K & 349 & $2.36(\mathrm{~S}-2)$ & $304(\mathrm{~S}-2)$ & 1.15 \\
\hline RIGID & 328 & $2.22(\mathrm{~S}-2)$ & $295(\mathrm{~S}-2)$ & 1.11 \\
\hline
\end{tabular}

Table 5 indicated that the smaller of the initial connection stiffness parameters the higher story drift and the performance point. In addition, the maximum story drift is obtained from linear analysis is always greater than obtained from nonlinear static procedure (NSP). However, The structural performance obtained from NSP is classified as damage control range (S-2) for all MR connections type, whereas the structural performance level exhibit varies from linear analysis., i.e., damage control range (S-2) for rigid and $M R-25 \bar{K}$ frames, life safety (S-3) for $M R-14 \bar{K}$, and limited safety range (S4) for $M R-10 \bar{K}$ and $M R-6 \bar{K}$, respectively.
Table 6. Comparison of the interstory drift index for $\mathrm{CB}$

\begin{tabular}{|c|c|c|c|c|}
\hline \multirow{2}{*}{$\begin{array}{c}\text { Type of } \\
\text { Connec. }\end{array}$} & \multicolumn{2}{|c|}{$\begin{array}{c}\text { Analysis first order } \\
\text { (linear) }\end{array}$} & \multicolumn{2}{c|}{$\begin{array}{c}\text { Pushover (nonlinear } \\
\text { static) }\end{array}$} \\
\cline { 2 - 5 } & $\begin{array}{c}\text { Max. } \\
\text { story } \\
\text { drift } \\
(\mathrm{mm}) \\
\text { using } \\
\mathrm{C}_{\mathrm{d}}=5\end{array}$ & $\begin{array}{c}\text { Inter-story } \\
\text { drift index } \\
(\%)\end{array}$ & $\begin{array}{c}\text { Perf. } \\
\text { point } \\
(\mathrm{mm})\end{array}$ & $\begin{array}{c}\text { Linear/ } \\
\text { Non- } \\
\text { linear }\end{array}$ \\
\hline CB-6K & 35.2 & $0.238(\mathrm{~S}-1)$ & $57.8(\mathrm{~S}-1)$ & 0.610 \\
\hline CB-10K & 35.2 & $0.238(\mathrm{~S}-1)$ & $57.7(\mathrm{~S}-1)$ & 0.610 \\
\hline CB-14K & 35.1 & $0.237(\mathrm{~S}-1)$ & $57.5(\mathrm{~S}-1)$ & 0.610 \\
\hline CB-25K & 35 & $0.236(\mathrm{~S}-1)$ & $57.1(\mathrm{~S}-1)$ & 0.613 \\
\hline
\end{tabular}

Further investigation, all CB frames show similar structural performance level either obtained from linear analysis of from nonlinear analysis. It can be seen from table 6 that all $\mathrm{CB}$ frames exhibit immediate occupancy level (S-1) of the structural performance level since drift index $<0.7 \%$. Moreover, the sensitivity of connections reduced significantly on the behaviour and performance frame due to present of the braces.

The calculation of expected maximum inelastic displacement from elastic displacement by multiply the elastic displacement with $C_{d}$ factor as stated in many codes, that are $C_{d}=5.5$ and $C_{d}=5$ for MRF and $\mathrm{CB}$ frames respectively. Although, $C_{d}$ factors are functions of structural over strength factor, structural ductility factor and damping ratio. Therefore, in this study the $C_{d}$ factors assume are not influenced by initial connection stiffness parameter.

\section{Conclusion}

Evaluation of behavior and performance of semi rigid frame for braced (CB) and unbraced (MR) is presented in this paper. Based on the results obtained from two types of frames (MR and $\mathrm{CB}$ ) that having different initial connection stiffness parameters, some conclusion can be drawn:

- The initial connection stiffness parameter plays a role on the behaviour and performance of the unbraced frame (MR). However, for the braced frame (CB) the effect is less significant compared with unbraced frame (MR).

- For the MR frame the results obtained from nonlinear static analysis close to linear analysis when the initial connection parameter increases, while for the CB frame is almost unaffected.

- The higher the initial connection stiffness parameter of MR frame, the smaller interstory drift index and the more ductile the frame behaviour. On the other hand, for the braced frame, interstory drift index and displacement ductility is almost not influenced by initial connection stiffness parameter especially for rigid connections.

- The structural performance obtained from NSP is classified as damage control range (S-2) for all MR 
connections type while for $\mathrm{CB}$ frames is classified as immediate occupancy (S-1).

\section{References}

1. AISC 360-10. Specification for structural buildings. American Institute of Steel Construction, Inc., Chicago (2010).

2. Eurocode 3., Structures in seismic region. Commission of the Eropean Communities (1990)

3. E. S. Kameshki and M. P. Saka, Optimum design of steel frames with semi-rigid connection using a genetic algorithm, Computer and Structures 79, 1593-1604 (2001).

4. F. Danesh, Seismic behavior of mixed structures. The $12^{\text {th }}$ World Conference on Earthquake Engineering, 190-195.

5. S. O. Degertekin and M. S. Hayalioglu, Design of non-linear semi-rigid steel frames with semi-rigid column bases. Electronic Journal of Structural Engineering, 4, 1-16 (2004)

6. W. F. Chen, Y. Goto, and J. Y. Liew, Stability Design of Semi-Rigid Frames, John Wiley and Sons, Inc (1996)

7. F. M. Mazzolani and V. Piluso, Theory and Design of Seismic Resistant Steel Frames, E \& FN SPON, An Imprint of Chapman and Hall, London (1995)

8. FEMA-356. Prestandard and Commentary for the Seismic Rehabilitation of Buildings. The American Society of Civil Engineers for the Federal Emergency Management Agency, Washington DC, USA (2000).

9. ASCE 41-13. Seismic Evaluation and Retrofit of Existing Buildings. ASCE Standard (2013)

10. H. Ghaffarzadeh, N. Talebian, and R. Kohandel, Journal of Earthquake Engineering and Engineering Vibration 12(3), 399-409 (2013).

11. S. K. Kunnath and E. Kalkan, ISET Journal of Earthquake Technology 41(1),159-181(2004).

12. R. T. Teruna, Comparison of seismic responses for reinforced concrete buildings with mass and stiffness irregularities using pushover and nonlinear time history analysis. Proceeding of IOP Conf. Ser.: Mater. Sci. Eng. 180012145 (2017). 